\title{
História
}

\section{Psicologia Escolar e Educacional em busca de novas perspectivas}

\author{
Educational and School Psychology: new perspectives
}

\author{
Marilene Proença Rebello de Souza
}

Apresentaremos a seguir a Conferência proferida pela Dra. Marilene Proença Rebello de Souza, presidente atual da ABRAPEE, durante as atividades científicas do VIII Congresso Nacional de Psicologia Escolar e Educacional, em 2007, realizado na Universidade Federal de São João Del Rei, intitulada Psicologia Escolar e Educacional em busca de novas perspectivas.

A área de Psicologia Escolar e Educacional é uma das áreas de pesquisa e de atuação profissional no campo da Psicologia tradicionalmente presente na história dessa ciência no Brasil. Do ponto de vista histórico, a Psicologia Escolar e Educacional permaneceram como campos distintos até muito recentemente: a primeira como o campo da prática profissional e a segunda enquanto área de pesquisa em Psicologia. Essa dicotomia passou a ser questionada por uma perspectiva crítica que considerava que teoria e prática são elementos indissociáveis na constituição de uma ciência dita humana.

As discussões advindas da década de 1980 passaram a repensar a tarefa do psicólogo, defendendo a necessidade de mudança nos referenciais teóricos na compreensão das questões escolares, com vistas a promover o desenvolvimento de práticas pedagógicas de melhor qualidade. Esse movimento de crítica fortaleceuse no campo da Psicologia Escolar e atualmente podemos considerar que temos, no Brasil, um conjunto de trabalhos de intervenção e de pesquisa que: a) rompe com a culpabilização das crianças, adolescentes e suas famílias pelas dificuldades escolares; b) constrói novos instrumentos de avaliação psicológica e de compreensão da queixa escolar; c) articula importantes ações no campo da formação de professores e de profissionais de saúde.

É possível afirmar que de fato se constitui uma corrente crítica no campo da Psicologia Escolar, considerando-a como área de estudos da Psicologia, de atuação e de formação do psicólogo que busca compreender o fenômeno educacional como produto das relações que se estabelecem no interior da escola. Escola essa atravessada pelas políticas educacionais, pela história local de sua constituição enquanto instituição e enquanto referência educacional e de aquisição de conhecimento pelos sujeitos que a constituem e nela se constituem.

A Psicologia se amplia para sua dimensão educativa e passa a se fazer presente nos mais diversos campos educacionais: na área da Criança e do Adolescente, atuando com projetos de inclusão social, planejamento de ações comunitárias e sociais, de ação junto a jovens em liberdade assistida; em programas na área do idoso; prevenção de doenças sexualmente transmissiveis e DST/ AIDS; no campo de programas governamentais e não governamentais de formação de educadores; nos órgãos de Controle Social, Fóruns Estaduais e Nacional, dentre outros. Mas essa ampliação no campo de atuação na direção da Educação não poderá se fortalecer se juntamente com ela não comparecerem as bases teóricas para a construção de uma prática de fato informada, qualificada e crítica.

Precisamos estar sempre atentos para responder às finalidades do trabalho que vimos desenvolvendo, discutindo e analisando por que e para que realizar uma determinada intervenção ou ação, sob pena de nos transformarmos em animadores ou educadores sociais ou técnicos qualificados, perdendo as especificidades do conhecimento psicológico a serviço da educação. Em seguida, detalharemos as ideias apresentadas.

\section{A Psicologia enquanto Profissão}

Iniciamos nossa fala destacando a importância da regulamentação da profissão de psicólogo, realizada em 1962, pela Lei no. 4119 de 27 de agosto. Esta regulamentação permitiu a institucionalização da profissão, a instauração de cursos de formação de psicólogos, dentre outros ganhos, mas também influenciou fortemente no modelo de formação que passou a ser instaurado nacionalmente. Este modelo foi fortemente centrado no caráter clínico e de profissional liberal do psicólogo, tendo, como centro da formação, disciplinas que enfatizam os conteúdos relativos ao Psicodiagnóstico, às Psicoterapias e às Técnicas de Exame Psicológico, 
priorizando o atendimento individual do cliente, nos moldes do modelo médico de consultório (Mello, 1978). Essa formação hegemônica levou à atrofia de outras áreas de atuação historicamente anteriores à própria prática clínica como as áreas das organizações e de psicologia educacional/escolar. De 78 psicólogos, no final da década de 1960, formados pela Faculdade de Filosofia Ciências e Letras da Universidade de São Paulo, chegamos até o momento a aproximadamente 130.000 profissionais no Brasil.

\section{Psicologia Escolar: início da discussão em busca de uma prática crítica}

A Psicologia Escolar foi uma das primeiras áreas no Brasil a esboçar uma crítica à formação profissional e ao modelo de atuação psicológica em educação. O trabalho pioneiro de Maria Helena Souza Patto, de 1981, intitulado Psicologia e Ideologia: uma introdução crítica à Psicologia Escolar demonstrava esta análise ao tecer as seguintes críticas: a) à concepção de ciência da Psicologia, centrada no positivismo, na Psicometria e na Psicologia Diferencial; b) às explicações a respeito das dificuldades de aprendizagem, focadas na criança e na teoria da Carência Cultural; c) ao modelo clínico, psicoterapêutico e reeducativo de atuação psicológica no atendimento à queixa escolar.

Tais críticas tiveram repercussões importantes para a área de Psicologia Escolar, destacando-se: a) a importância de pesquisarmos os fenômenos educacionais a partir dos processos que acontecem no interior da escola; b) a necessidade de encontrar modelos teórico-metológicos que superassem a noção unilateral de adaptação da criança ao sistema escolar; c) o destaque para a necessidade de autonomia do trabalho do psicólogo em relação ao corpo dirigente da instituição escolar; d) a reconstituição da identidade do psicólogo no campo da educação.

A discussão posta nos anos 1980 amplia-se nas décadas posteriores e chegamos aos anos 2000 discutindo duas importantes dimensões no campo da Psicologia Escolar e Educacional: a) a necessidade da Psicologia buscar na Educação concepções progressistas que contribuam para o entendimento do que é o homem concreto (como produto das relações sociais - no nível da sociedade mais ampla) (Tanamachi, 2000); b) a necessidade de se buscar no interior da Psicologia pressupostos teórico-metodológicos que permitam analisar criticamente temas e teorias que possibilitem compreender o encontro do sujeito humano com a educação (Meira, 2000). As questões postas a partir da crítica à psicologia adaptacionista possibilitaram, nos anos 1990, pesquisas sobre os seguintes temas: a) fracasso escolar; b) identidade profissional; c) escolarização do deficiente mental; d) formação profissional; e) atuação profissional na educação em uma perspectiva crítica; f) avaliação psicológica de problemas escolares; g) vida diária escolar, dentre outros.

O aprofundamento das discussões no âmbito da Psicologia Escolar e Educacional permitiu que a área produzisse estudos que levaram à elaboração de elementos constitutivos de uma atuação/formação em Psicologia Escolar em uma perspectiva crítica (Checchia \& Souza, 2003), a saber: a) Compromisso político do psicólogo com a luta por uma escola democrática e de qualidade social; b) ruptura epistemológica com concepções adaptativas de Psicologia na direção de uma Psicologia Crítica; c) construção de uma práxis psicológica frente à queixa escolar. A seguir, detalharemos cada um desses elementos.

No que se refere ao compromisso político do psicólogo com a luta por uma escola democrática e de qualidade social, destaca-se o resgate da função social da escola em uma perspectiva histórico-crítica que remete à: a) formação do pensamento científico; b) formação do cidadão crítico; c) ampliação da socialização e da difusão de valores na direção da sociedade democrática.

Quanto à ruptura epistemológica com concepções adaptativas de Psicologia na direção de uma Psicologia Crítica, houve um intenso movimento na área pela busca de referenciais teórico-metodológicos no campo da Psicologia da Educação que compreendam: a) os fenômenos escolares enquanto produtos do processo de escolarização, constituídos pelas dimensões institucional, pedagógica e relacional; b) o desenvolvimento humano e a aprendizagem enquanto processos inseparáveis, articulando as dimensões biológica, psicológica e histórica dos indivíduos; c) a necessidade de construir instrumentos psicológicos de aproximação e de conhecimento da realidade que permitam compreender a complexidade dos fenômenos educativos; d) a consideração da dimensão educativa no trabalho psicológico.

A construção de uma práxis psicológica frente à queixa escolar deverá considerar como fundamentais: a) a demanda escolar/educacional como ponto de partida de uma ação na escola/instituição educativa que precisa ser compartilhada ; b) o trabalho participativo com todos os setores do processo educativo; c) o fortalecimento do trabalho do professor/ educador; d) a análise coletiva dos diferentes discursos presentes na escola/instituição educativa e nos processos escolares/educacionais em busca do enfrentamento dos desafios produzidos pela demanda escolar/educativa.

\section{Em que dimensões se inserem as novas perspectivas em Psicologia Escolar e Educacional?}

As novas perspectivas em Psicologia Escolar e Educacional referem-se à: a) mudança nas perguntas advinda da ruptura epistemológica, permitindo compreender a dimensão educativa do trabalho do psicólogo; b) ampliação das áreas tradicionais de atuação do psicólogo no campo da educação; c) construção de referentes teóricos para uma prática psicológica que considere as dimensões individuais, sociais e históricas do processo de escolarização.

Os avanços teórico-metodológicos da Psicologia Escolar e Educacional trouxeram a possibilidade de construir um novo objeto de estudo para a área, centrado no encontro do psicólogo com a educação. Assim sendo, há várias propostas 
de modalidades de intervenção/atuação profissional no campo educativo. Ressaltaremos algumas delas. Algumas áreas de atuação são clássicas em Psicologia Escolar e educacional, tais como as instituições escolares e o ensino de psicologia. Quanto a outras áreas, vamos denominá-las emergentes, destacando-se: instituições educativas; educação inclusiva de pessoas com deficiência; direitos da criança e do adolescente e direitos humanos; educação e saúde.

No que se refere à atuação do psicólogo nas instituições escolares, após as críticas dos anos 1990, tivemos uma retração da contratação de profissionais no campo da educação. Ao fazer a autocrítica sobre os modelos e práticas de atuação da Psicologia no campo da educação, a Psicologia Escolar passou por momentos de "crise", deixando de atuar mais amplamente nos setores educacionais, principalmente nos públicos. De maneira geral, esse espaço tem sido ocupado pela Psicopedagogia, cuja prática tem reeditado a concepção clínica de atendimento à chamada "criança com dificuldades escolares", atribuindo rótulos sofisticados de transtornos de déficit de atenção e de hiperatividade, abrindo espaços para a patologização/ medicalização do processo de escolarização. O desafio agora principal da Psicologia Escolar é o de superação desse momento de crítica, considerando que já existem propostas interessantes e críticas de intervenção no campo da educação e estas propostas precisam se tornar mais visíveis entre os psicólogos e socialmente.

O Ensino de Psicologia tem se constituído em um espaço eminentemente de formação, de socialização do conhecimento acumulado no campo da Psicologia, de reflexão sobre a constituição da subjetividade humana. Ao adentrarmos ao campo do Ensino da Psicologia, estamos possibilitando estudar a complexidade da formação do ser humano, do que nos permite construir a cultura, os valores, os sentimentos, os sentidos e os significados, que nos permitem interpretar o mundo que está a nossa volta, desnaturalizando o estabelecido, mostrando sua dimensão histórico-social, analisando as relações de poder, de constituição das instituições, incluindo a escola e as relações sociais que nela se estabelecem. Quando se trata de Ensino de Psicologia, lato sensu, estamos nos referindo também às Licenciaturas, aos cursos de formação em Nível Superior em que a Psicologia se faz presente. O trabalho do psicólogo no Ensino não é um trabalho de intervenção psicológica, mas sim de problematizar e discutir questões que são, de alguma maneira, referentes à Psicologia enquanto campo de atuação e de conhecimento. No nível do Ensino Médio, temos um grande desafio posto pela LDBEN (1996) que retirou a obrigatoriedade da Psicologia neste nível de ensino.

Nas áreas emergentes, consideramos a educação inclusiva da pessoa com deficiência. A educação inclusiva defende o direito à escolarização para todos, incluindo crianças com necessidades educativas especiais. Esta posição político-pedagógica presente na Declaração de Salamanca (1994), documento internacional do qual o Brasil é país signatário, traça diretrizes e linhas de ação para que se possa atuar no campo da educação e da escolarização de crianças e adolescentes. Trabalhar nesta direção é fundamental para a Psicologia. Como incluir uma criança na escola? Quais os desafios a serem enfrentados? São algumas das questões postas para nós.

No campo dos direitos da Criança e do Adolescente e dos Direitos Humanos, consideramos que este se fortaleceu com o Estatuto da Criança e do Adolescente (1990), que possibilita a garantia de direitos bem como regula a questão do jovem em conflito com a lei e de medidas socioeducativas. A aprovação do Plano Nacional de Educação para os Direitos Humanos também contribuirá para fortalecer esta importante área de atuação e formação do psicólogo. Precisamos ainda saber o que são direitos sociais, individuais e como exigilos para todos os segmentos sociais. Trabalhos recentes de psicólogos em Ribeirão Preto, São Paulo e Vitória, de atuação junto a conselhos tutelares, bem como de atuação frente aos CEDECAS e demais órgãos de acompanhamento do adolescente, têm demonstrado a importância da Psicologia levar os seus conhecimentos. A atuação junto ao campo da Assistência social e das medidas socioeducativas no campo do direito da criança e do adolescente e de medidas de proteção à criança e ao adolescente (SUAS) serão importantes espaços a serem construídos e consolidados pelo psicólogo escolar. A atuação junto a instituições que atuam no campo dos cuidados - casas abrigo, instituições para idosos; pessoas com deficiências, sofrimento mental, dentre outras - são bons exemplos de possibilidades de trabalho da Psicologia Escolar.

Tratar a questão dos encaminhamentos escolares como encaminhamentos da escola, buscando compreender como se processa a escolarização, é ainda um importante desafio para a Psicologia Escolar e Educacional. Será necessário, cada vez mais, lutar pela importância de compreender a queixa escolar não como mero reflexo de problemas emocionais, mas sim como fruto das relações escolares e rever o processo diagnóstico e seus instrumentos de avaliação, sob pena de darmos destinos que vão constituindo um indivíduo que se distancia cada vez mais da sua condição de ser humano e ser de direitos. Além disso, precisaremos articular ações no plano da formação profissional com as Clínicas-Escola para o atendimento de queixas escolares e articular ações entre os psicólogos que atuam na área da educação com os que se encontram na área da saúde, ampliando a compreensão do processo de escolarização e sua importância na constituição dos indivíduos.

Por fim, é importante ressaltar que precisamos trabalhar e estar sempre atentos para responder às finalidades do trabalho que vimos desenvolvendo, discutindo e analisando por que e para que realizar uma determinada intervenção ou ação, sob pena de nos transformarmos em animadores ou educadores sociais ou técnicos qualificados, perdendo as especificidades do conhecimento psicológico a serviço da educação.

O compromisso profissional do psicólogo com uma concepção política emancipatória também implica uma ética profissional que reside na indignação diante da humilhação 
e das práticas disciplinares e pedagógicas que retiram do sujeito o seu status de ser humano. Ao considerar a não naturalização das ações humanas, das práticas sociais e pedagógicas, essa ética possibilita o aprofundamento da crítica teórico-metodológica no campo do conhecimento da Psicologia. As perspectivas de uma área profissional como a Psicologia Escolar e Educacional estão, necessariamente, articuladas às respostas que pudermos produzir aos desafios postos pela demandas sociais e institucionais. Por fim, consideramos importante a participação dos psicólogos escolares e educacionais nos espaços organizativos e políticos, bem como na construção de políticas públicas na área da educação, tais como: associações de classe; fóruns de discussão; conselhos de representantes e órgãos de controle social.

Assim, consideramos que o conhecimento psicológico no campo da educação precisa ser constantemente construído, revisitado, criticado, superado, visando dar respostas e interferir, o mais que pudermos, nos rumos das dimensões de formação do sujeito humano.

\section{Referências}

Brasil. (1990). Lei de Diretrizes e Bases da Educação Nacional. Lei $n^{\circ} 9394$ de 20 de dezembro de 1996. Recuperado: 29 fev. 2008. Disponível: portal.mec.gov.br/seesp/ index2. php?option $=$ content $\&$ do_pdf $=1 \&$ id $=63 \&$ banco $=$.

Brasil. (1999). Estatuto da Criança e do Adolescente. Lei no. 8.069, de 13 de julho de 1990. 29 Recuperado: Fev. 2008.Disponível: http://www.planalto.gov.br/ccivil_03/Leis/L8069.htm.

Brasil. (2008). Declaração de Salamanca. Sobre Princípios, Políticas e Práticas na Área das Necessidades Educativas Especiais. Recuperado: 29 fev. 2008. Disponível: portal.mec.gov.br/seesp/ arquivos/pdf/salamanca.pdf.

Meira, M. E. M. (2002). Psicologia Escolar: pensamento crítico e práticas profissionais. Em E. R. Tanamachi, M. Proença, \& M. Rocha (Orgs.), Psicologia e Educação: Desafios teórico-práticos (pp. 35-72). (2a ed.). São Paulo: Casa do Psicólogo.

Mello, S. L. (1978). Psicologia e profissão em São Paulo. São Paulo, Ática.

Patto, M. H. S. (1984). Psicologia e Ideologia: uma introdução crítica à Psicologia. São Paulo: T.A. Queiroz.

Souza, M. P. R., \& Checchia, A. K. A. (2003). Queixa escolar e atuação profissional: apontamentos para a formação de psicólogos. Em M. E. M. Meira, \& M. Antunes (Orgs.), Psicologia Escolar: Teorias críticas (pp. 105-137). São Paulo: Casa do Psicólogo.

Tanamachi, E. R. (2000). Mediações teórico-práticas de uma visão crítica em Psicologia Escolar. Em E. R. Tanamachi, M. Proença, \& M. Rocha (Orgs.), Psicologia e Educação: Desafios teóricos práticos (pp. 73-104). São Paulo: Casa do Psicólogo.

Marilene Proença Rebello de Souza

Doutora e Docente do Instituto de Psicologia da Universidade de São Paulo. 